\title{
An Engineering Project Management System Design of Fengyun Meteorological Satellite
}

\author{
Zhaohui Chenga, Manyun Lin, You Ma, Cunqun Fan ${ }^{\text {b,* }}$ \\ National Satellite Meteorological Centre, Beijing, China \\ a email:chengzh@cma.gov.cn, ${ }^{b}$ email:fancq@cma.gov.cn \\ *corresponding author
}

Keywords: meteorological satellite; engineering system; management efficiency; key technology

Abstract: Fengyun Meteorological Satellite Engineering System has the characteristics of long construction period, huge investment, and complicated user roles involved in the project, and accumulated data and documents during project construction. In order to coordinate the management of the system and improve management efficiency, this article has designed Fengyun satellite engineering project management system. The design includes the system framework, key technologies and module functions. Through the design of this system, Fengyun satellite engineering system management is more simple and efficient.

\section{Introduction}

With the launch of Fengyun No. 3 batch of 02 satellites, China's second generation polar-orbiting meteorological satellite ground application system will gradually realize the operational operation model from experimental to business, from single-star observation to multi-satellite network observation. The Fengyun No. 3 Batch 02 Application Platform will inherit the successful technological achievements of the Fengyun No. 3 batch of ground application systems, add new instrument reception processing capabilities, build a new computer network support system, and expand the ground station, ground receiving equipment, and infrastructure. The software system performs function expansion and adaptation. Fengyun No. 3 Batch 02 application system needs to build data receiving system, operation control system, data preprocessing system, product generation system, product quality inspection and verification system, computer and network system, data archiving and service system, monitoring and analysis service system, and application. Demonstration system and simulation and development system 10 technical systems, large-scale tests, and civil engineering and supporting facilities supporting the operation of the system.

The Fengyun No. 3 Batch 02 application system has the characteristics of long construction period, huge investment, complicated user roles involved in the project, and accumulated data and documents during project construction. Focusing on these management priorities and difficulties, the Fengyun Satellite Engineering Project Management System has fully coordinated and efficiently managed the Fengyun No. 3 batch of meteorological satellite ground application system 
engineering projects managed by the National Satellite Meteorological Center from project initiation to project planning, project implementation, and project monitoring. The project completed the entire project flow. At the same time, the system implements document management, schedule management, budget management, and problem management.

\section{System Framework}

Fengyun satellite engineering project management system is divided from the perspective of applications and is divided into: infrastructure layer, data layer, platform support layer, application layer, and user layer.

User layer: It includes the general commander, chief and deputy chief engineer, management staff (engineering office and supervision), technical staff (leader or deputy chief designer) and system administrator.

Application layer: It consists of three sub-systems: project management sub-system, document management sub-system and back-office management sub-system.

Platform support layer: Provides technical support for the service application layer and includes the message engine, report service, knowledge base service, correlation analysis engine, search engine, real-time analysis service, and monitoring service.

Data layer: It contains project information database, document information database, support library and monitoring library.

Infrastructure layer: It includes basic software and hardware support such as WEB server, data server and operating system.

The business process of the system includes project management business process, document management business process and system management process, and the roles are divided into project management personnel, technical personnel and system administrators. The project management business process chart is shown as in Fig. 1.

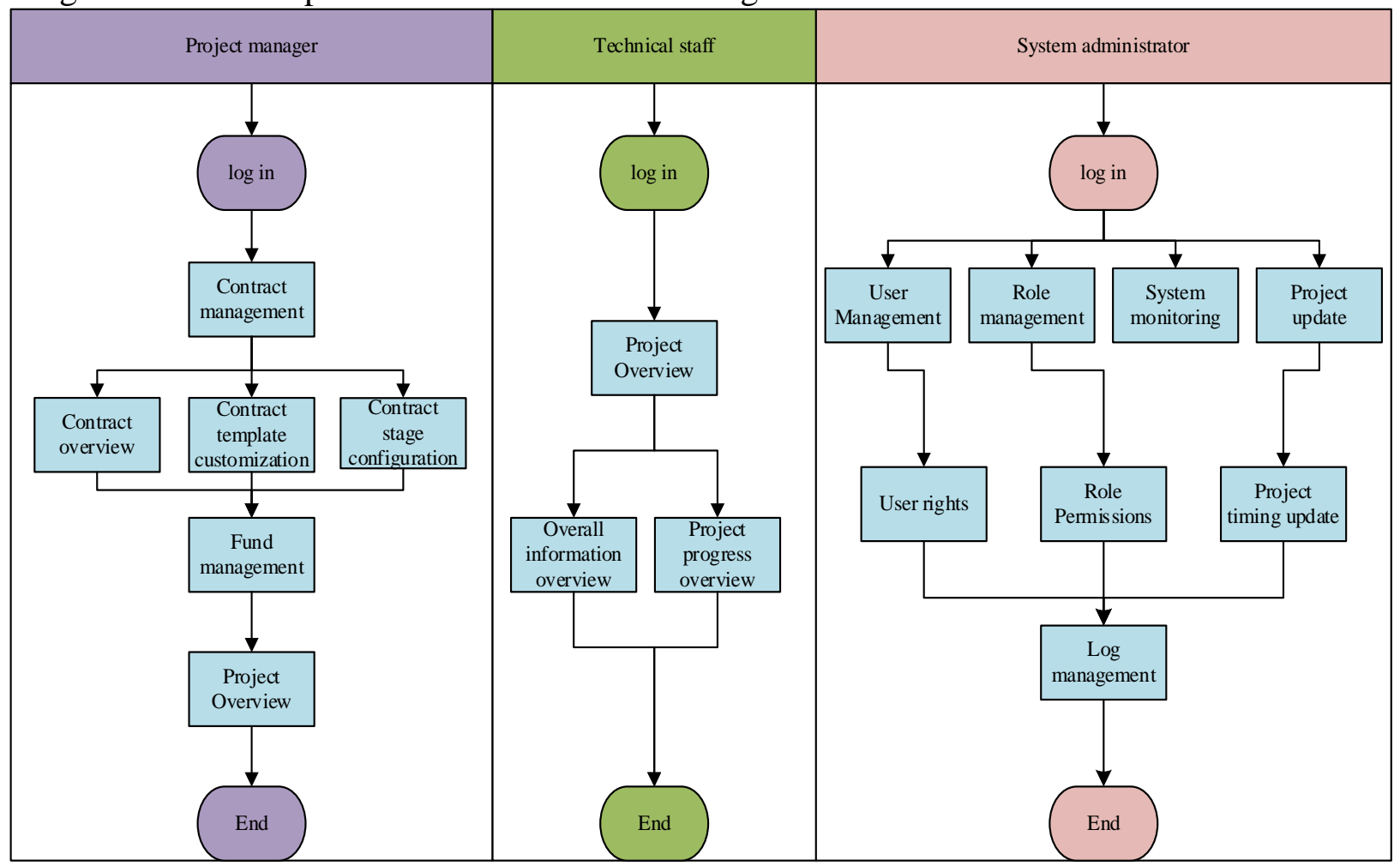

Figure 1 Scheduled scheduling process 


\section{Key Technologies}

(1) B/S multi-layer architecture: Users can access the system and conduct business operations anywhere, any computer connected to the Meteorological Centre intranet;

(2) J2EE software development standards: The J2EE-based software development system is a stable, secure, efficient, and scalable software system;

(3) Application service technology based on Web Service: Through the use of advanced Web Service technology, some basic and common service interfaces are developed, so that the system adopts the interface service mode to provide integrated service management;

(4) Keepalive+MySQL-based database master-slave hot standby: Use Keepalived to provide virtual IP (VIP), applications connect VIPs, VIPs connect to database A, and perform replication synchronization from A to B. When A machine crashes, Keepalived migrates the connection address of the VIP to database B and executes Replication synchronization from B to A. Ensure that user data is not lost, and the system is long-term, stable, and safe to operate;

(5) Perform scheduled tasks based on the Spring@Scheduled annotation. Ensure the timely acquisition of new data and new news so that the program can run normally;

(6) Permissions: Basic user permissions (item permissions), role permissions (menu permissions + button permissions + simple data permissions).

\section{Project System Functions}

The system is mainly composed of three parts, including the project management subsystem, document management subsystem and background management subsystem.

The project management subsystem mainly includes project management database generation, project overview management, contract information management, and expense information management.

The Document Management Subsystem realizes the collection, management and retrieval of various documents and results generated during the implementation of Fengyun Satellite Engineering Project. The contents of the document include: project process documents, various types of approval documents in the project process, development task books, technical program design documents, contract documents, tender documents, software requirements analysis, outline design, test reports, interface documents, product prototype algorithms, and acceptance Documents and document templates.

Background management sub-systems to achieve user management and system operation monitoring and management. User management includes user data management, rights management, and role management. System operation and monitoring management includes: monitoring of CPU usage, memory usage, memory usage, and network bandwidth.

(1) The project overview module mainly previews the project and contract information under the system, and summarizes the completion of the project contract information. It includes all the project items in the system, and obtains the list of contract information under the project by selecting the project, and selects the contract to obtain the contract. Stage information, each stage contains documents that should be submitted and related amounts.

(2) The contract management module is used to display all contract information. The main functions include the review of contract information, Excel export, and fuzzy query. Through the contract payment plan customization phase configuration, you can select the appropriate contract template to match the phase. Contract templates can be customized.

(3) Fund management is mainly used to display the actual payment time and payment amount of the contract, and to display the budget amount and executed amount of each subject. 
(4) Document management is mainly used for users to submit relevant documents: it is mainly divided into document submission, replacement and downloading related to the contract establishment phase and construction phase, management of the documents and meetings of the ten major systems, and exporting new contracts for the time period according to the time.

(5) System monitoring Logs are used to obtain system memory, store information, and user operations in the current system in real time.

(6) The system management is used for the management of users, personnel information, departments, and roles of the system, as well as the manual and regular acquisition of project directories and announcements and notifications for system information reminders.

\section{Conclusions}

The system can provide comprehensive, accurate and timely visual monitoring of project information to achieve real-time tracking of project problems. The system eliminates islands of business information, realizes smooth flow of top-down and bottom-up information, and realizes the accumulation, sharing, and reuse of project documents, results, and project knowledge. The system can help project management personnel to achieve the dynamic management of the project; improve the project completion rate on time and improve the execution quality of the project.

\section{References}

[1] JunYang, PengZhang, NaimengLu, et al. Improvements on global meteorological observations from the current Fengyun 3 satellites and beyond[J]. International Journal of Digital Earth, 2012, 5(3):251-265.

[2] Zhang P, Yang H, Qiu H, et al. Quantitative Remote Sensing from the Current Fengyun 3 Satellites[J]. Advances in Meteorological Science \& Technology, 2012.

[3] Xia M, Li T, Zhang Y, et al. Closed-loop design evolution of engineering system using condition monitoring through internet of things and cloud computing[J]. Computer Networks the International Journal of Computer \& Telecommunications Networking, 2016, 101(C):5-18.

[4] Lefticaru R, Konur S, Yildirim U, et al. Towards an Integrated Approach to Verification and Model-Based Testing in System Engineering[C]// IEEE International Conference on Internet of Things. IEEE, 2018.

[5] Shieh M D, Li Y, Yang C C. Comparison of multi-objective evolutionary algorithms in hybrid Kansei engineering system for product form design[J]. Advanced Engineering Informatics, 2018, 36:31-42. 